9-1-2008

\title{
Teacher Turnover: Examining Exit Attrition, Teaching Area Transfer, and School Migration
}

\author{
Ed Boe \\ Univer. of Pennsylvania, boe@gse.upenn.edu \\ Lynne H. Cook \\ California State University \\ Robert J. Sunderland \\ University of Pennsylvania
}

Follow this and additional works at: https://repository.upenn.edu/gse_pubs

Part of the Education Commons

\section{Recommended Citation}

Boe, E., Cook, L. H., \& Sunderland, R. J. (2008). Teacher Turnover: Examining Exit Attrition, Teaching Area Transfer, and School Migration. Retrieved from https://repository.upenn.edu/gse_pubs/184

Reprinted from Exceptional Child, Volume 75, Issue 1, September 2008, pages 7-31.

We have contacted the publisher regarding the deposit of this paper in ScholarlyCommons@Penn. No response has been received.

This paper is posted at ScholarlyCommons. https://repository.upenn.edu/gse_pubs/184

For more information, please contact repository@pobox.upenn.edu. 


\title{
Teacher Turnover: Examining Exit Attrition, Teaching Area Transfer, and School Migration
}

\author{
Abstract \\ The purposes of this research were to quantify trends in three components of teacher turnover and to \\ investigate claims of excessive teacher turnover as the predominant source of teacher shortages. \\ Attrition and teaching area transfer rates were comparable in special and general education and \\ increased substantially from 1991-1992 to 2000-2001. School migration was stable over years, but higher \\ in special than general education. Although annual turnover was high and increased to 1 in 4 teachers \\ (25.6\%) by 2000-2001, teacher attrition was lower than in other occupations. Evidence suggests that \\ retention is unlikely to increase without dramatic improvements in the organization, management, and \\ funding of public schools. Until then, an increased supply of qualified teachers is needed to reduce \\ teacher shortages. \\ Disciplines \\ Education

\section{Comments} \\ Reprinted from Exceptional Child, Volume 75, Issue 1, September 2008, pages 7-31. \\ We have contacted the publisher regarding the deposit of this paper in ScholarlyCommons@Penn. No \\ response has been received.
}




\section{Teacher Turnover: Examining Exit Attrition, Teaching Area Transfer, and School Migration}

ERLING E. BOE

University of Pennsylvania

LYNNE H. COOK

California State University Dominguez Hills

ROBERT J. SUNDERLAND

University of Pennsylvania

Aвstract: The purposes of this research were to quantify trends in three components of teacher turnover and to investigate claims of excessive teacher turnover as the predominant source of teacher shortages. Attrition and teaching area transfer rates were comparable in special and general education and increased substantially from 1991-1992 to 2000-2001. School migration was stable over years, but higher in special than general education. Although annual turnover was high and increased to 1 in 4 teachers (25.6\%) by 2000-2001, teacher attrition was lower than in other occupations. Evidence suggests that retention is unlikely to increase without dramatic improvements in the organization, management, and funding of public schools. Until then, an increased supply of qualified teachers is needed to reduce teacher shortages.



uring the past decade or so, teacher turnover has become a major concern in educational research and policy analysis because of the demand it creates for replacement teachers (Johnson, Berg, \& Donaldson, 2005; Kozleski, Mainzer, Deshler, \& Coleman, 2000; National Commission on Teaching and America's Future, NCTAF, 2003). This concern is dramatized by NCTAF's assertion that "Teacher Retention Has Become a National Crisis" (p. 21 chapter heading), meaning that inadequate retention (i.e., excessive turnover) has become a crisis. Others have endorsed this per- spective and stated that the apparent shortage of teachers is due to exceptionally high demand created by an excessive rate of turnover, rather than because of insufficient supply. They believe that the teacher shortage is a myth, claiming that the supply of teachers is adequate (Ingersoll, 1997; NCTAF; Podgursky, 2006). This perspective does not have wide support; teacher shortage is commonly viewed as an imbalance between supply and demand (e.g., Boe \& Gilford, 1992; Curran \& Abrahams, 2000). The main purposes of this research were to quantify trends in teacher turnover phenomena nationally in special and general education and to investigate claims of 
excessive teacher turnover as the predominant source of teacher shortages.

Teacher turnover refers to major changes in a teacher's assignment from one school year to the next. Turnover includes three components, the most studied of which are leaving teaching employment (commonly referred to as attrition) and moving to a different school (commonly referred to as school transfer or as teacher migration). A third, but neglected, component is teaching area transfer, such as the transfer of a teacher from an assignment in special education to one in general education. This has been of particular concern to the field of special education (Kozleski et al., 2000), albeit little studied.

The results of research on teacher turnover have been used to support advocacy for far-reaching changes in education. At the policy level, NCTAF (2003) recommended downsizing schools, offering federal financial incentives for attracting teachers into high-shortage areas, and higher teacher compensation-all of which are designed to reduce teacher turnover. Kozleski et al. (2000) recommended the preparation of sufficient numbers of teachers in special education to fill the demand created by turnover. At the practice level, Kozleski et al. and Billingsley (2005) suggested a number of strategies including effective professional development and reasonable work assignments to enhance teacher retention. In view of this widespread use of research to advocate changes in policy and practice, it is important to have valid, comprehensive, and up-to-date evidence about the turnover of both special education teachers (SETs) and general education teachers (GETs). Yet much is not known, and there are several fundamental issues with the reporting, interpretation, and application of teacher turnover statistics.

\section{TURNOVER RATES}

Even though the teaching profession has been characterized as a revolving door (e.g., Hanushek, Kain, \& Rivkin, 2004; Ingersoll, 2003), there is some uncertainty and confusion about the amount of turnover annually. It is surprising that two major recent reviews of research literature on teacher turnover and retention (Billingsley, 2004;
Guarino, Santibañez, \& Daley, 2006) did not address the amount of turnover. Instead, these reviews focused on factors related to turnover and retention. A third recent review (Johnson et al., 2005) cited some of the extensive data on teacher attrition and migration collected by the National Center for Education Statistics (NCES) as part of its periodic national-level Teacher Follow-Up Surveys (TFS). TFS is a high-quality survey that defines attrition and migration behaviorally by tracking changes in an individual teacher's employment status from one year to the next, as distinguished from simply asking teachers about their intentions to remain or leave in the future. Furthermore, the sample sizes are reasonably large, and the response rates are quite high (Luekens, Lyter, \& Fox, 2004).

Based on TFS data from school years $1999-2000$ to $2000-2001,7.4 \%$ of all public school teachers left teaching employment, whereas another $7.7 \%$ moved to a different school-a total of $15.1 \%$ at the school level for attrition and migration combined (Luekens et al., 2004). Contrasted with these statistics, an influential report on America's teachers reported questionable or confusing data of uncertain origin about teacher transitions (NCTAF, 2003). According to NCTAF, $30 \%$ of the national teaching force was in transition at the school level during the 1999-2000 school year (15\% being hired; $15 \%$ leaving). In fact, however, only about $15 \%$ of the teaching force was in transition, not the $30 \%$ claimed. This is because the $15 \%$ hired at the school level one year replaced the $15 \%$ that left after the prior school year. The remaining $85 \%$ of the teaching force remained in the same school from one year to the next (Luekens et al.). The source of NCTAF's data is not known because the original research cited (Ingersoll, 2001) did not include such information.

\section{TURNOVER OF TEACHERS IN SPECIAL VERSUS GENERAL EDUCATION}

Based on TFS data for the 1993-1994 school year, Boe, Bobbitt, Cook, and Barkanic (1998) reported separate annual attrition percentages for SETs (6.3\%) and GETs (6.6\%). Contrasted with 
these statistics, a major report by the Council for Exceptional Children (Kozleski et al., 2000) stated that SETs leave the profession each year "at almost twice the rate of their general education colleagues" (p. 7), without citing the source of this information. This statement is certainly at odds with national TFS attrition statistics for leaving teaching employment. However, Kozleski et al. may have meant that twice as many leave teaching in special education (i.e., the sum of attrition and transfers to general education) as leave teaching in general education (i.e., the sum of attrition and transfers to special education). In that case, TFS data for 1994-1995 demonstrated that about twice as many teachers left special education teaching $(15.3 \%)$ as left general education teaching (7.0\%; Boe et al., 1998). Regardless, depending on what was meant, the Kozleski et al. statement is either ambiguous or incorrect.

\section{ATTRITION OF BEGINNING TEACHERS}

In addition to the concern about the annual attrition rate for all teachers, the even higher rate of attrition of beginning teachers has been particularly troubling to the field of education. According to TFS data for 2000-2001, 8.5\% of public school teachers with 1 to 3 years of full-time teaching experience left teaching employment annually, whereas $6.5 \%$ of teachers with 4 to 9 years of experience left annually (Luekens et al., 2004). Based on these data, the estimated rate of leaving during the first 3 years was $25.5 \%$, during the first 4 years was $32.0 \%$, and during the first 5 years was $38.5 \%$. In addition to TFS, NCES conducted the Baccalaureate and Beyond $(B \& B)$ Longitudinal Study during the mid-1990s and found annual attrition of only $6.9 \%$ for public and private teachers (combined) with 1 to 3 years of teaching experience (Henke, Chen, Geis, \& Knepper, 2000). This survey was based on a national sample of bachelor's degree graduates who entered teaching within a year of graduating.

Contrasted with these attrition statistics, Kozleski et al. (2000) reported that, "Four out of every ten entering special educators have left before their fifth year" (p. 5) -a 4-year rate of $40 \%$. Although SETs might have left teaching at a higher rate during their first 4 years than the 32\% reported by Luekens et al. (2004) for all public teachers, it is not possible to verify the $40 \%$ rate reported by Kozleski et al. for SETs because no data source was cited.

NCTAF (2003) has also reported questionable attrition data for early-career teachers. According to NCTAF, approximately $46 \%$ of all teachers leave during the first 5 years. This percentage was based on preliminary data from the 2000-2001 TFS (see Figure 4 note, p. 157). Although NCTAF cited Ingersoll (2002) as the original source of the $46 \%$ attrition rate, Ingersoll instead reported $39 \%$ attrition during the first 5 years of teaching experience based on TFS data but did not report the TFS year on which the $39 \%$ rate was based.

In spite of these ambiguities, NCTAF's (2003) conclusion that "almost half (of America's teachers) may leave during the first five years" (p. 24) has been widely repeated, sometimes without citing a source (e.g., Center on Education Policy, 2006; Smith \& Ingersoll, 2004; The Teaching Commission, 2006). This conclusion may not be a good estimate because it was based on preliminary TFS data for 2000-2001. Furthermore, it certainly does not represent the core of America's teaching force-full-time public school teachers. The $46 \%$ rate apparently includes private school teachers and part-time teachers, who are known to leave teaching employment at a substantially higher rate than public school teachers and fulltime teachers (Luekens et al., 2004).

\section{TEACHER TURNOVER COMPARED WITH OTHER OCCUPATIONS}

In addition to research on teacher turnover rates, efforts have been made to compare turnover rates in teaching and other occupations. The Bureau of National Affairs (BNA) publishes quarterly data on employee turnover nationally (e.g., 2002). BNA defines turnover as leaving the employing organization (this includes migrating to another organization in the same occupation and leaving the occupation), excluding reductions in force. For convenience, we call this corporate attrition, because it is based on leaving an employing organization and excludes transfers between sites 
within the organization. According to BNA (2002), the corporate attrition rate in 2000 for all employees was $15.6 \%$.

By comparison, the combined rate of public school teacher attrition (7.4\%) and school migration $(7.7 \%)$ was $15.1 \%$, based on TFS data for 2000-2001. However, almost half of this school migration percentage $(3.6 \%$ of the $7.7 \%$ ) was transfers between schools within the same district (Luekens et al., 2004). In addition, reductions in force account for a small component of the teacher attrition percentage (Whitener et al., 1997). Thus, the properly adjusted corporate attrition rate for public teachers in 2000-2001 was approximately $11.5 \%$; that is, the sum of teacher attrition and migration, less school transfers within a district. With these adjustments, the corporate attrition rate of $11.5 \%$ for public teachers was well below the BNA rate of $15.6 \%$ in 2000 for employees in all occupations - thus, attrition from public school teaching was about $4 \%$ lower than attrition from other occupations.

In contrast, NCTAF (2003, Figure 3) reported a corporate attrition rate of $11.9 \%$ for employees in all "nonteaching" occupations during the years 1998-2001, and a $15.7 \%$ turnover rate (movers plus leavers) for all public and private school teachers for 2000-2001, indicating that turnover in the teaching force was about $4 \%$ higher than in other occupations. The $11.9 \%$ apparently applied to all occupations; BNA does not report corporate attrition for nonteaching occupations per se. Though NCTAF cited Ingersoll (2002) as the source of their turnover rates, Ingersoll actually reported a nationwide average of $11 \%$ based on BNA data for all employees during the decade prior to 2002 , and $17 \%$ turnover for all teachers based on preliminary 2000-2001 TFS data. The correct mean corporate attrition rate for all employees during the years 1998-2001 was $14.1 \%$ (see BNA, 1999, 2000, 2001, 2002), not the $11.9 \%$ reported by NCTAF. The directly comparable corporate attrition rate for all teachers (public and private) was $13 \%$ based on Ingersoll's turnover estimate of $17 \%$, as adjusted downward for school transfers within public school districts, not the $15.7 \%$ reported by NCTAF. Thus computed, the corporate attrition of all teachers (public and private) was less than that of all employees.

\section{REASONS FOR LEAVING TEACH ING}

In conceptualizing interventions that hold promise for improving retention, researchers focus on the question of why teachers leave teaching (Billingsley, 2005; Kozleski et al., 2000; NCTAF, 2003). According to national attrition data from 1994-1995 TFS for public school teachers, some of the main reasons for leaving were a variety of personal and family considerations $(31 \%)$, poor health $(5 \%)$, and school staffing actions (3\%). Retirement accounted for $27 \%$. Only $24 \%$ of exiting public reachers wanted to escape from teaching (i.e., to pursue employment in other vocations or because of dissatisfaction with teaching) as their main reason for leaving (Whitener et al., 1997).

One of the complications in understanding why teachers leave is the treatment of teacher retirement. Ingersoll (2002) reported that "Contrary to conventional wisdom, retirement is not an especially prominent factor. It actually accounts for only a small part (12\%) of total turnover" of public and private teachers (p. 25).

\section{One of the complications in understanding why teachers leave is the treatment of teacher retirement.}

For Ingersoll, the base for computing the retirement percentage was "total turnover" - that is, the sum of all teachers who leave and who migrate to different schools. By contrast, the base for computing the retirement percentage used by Luekens et al. (2004) was just the number of teachers who leave. According to 2000-2001 TFS data, $30 \%$ of public school teachers who actually left teaching collected a pension from a teacher retirement system (Luekens et al.). Thus, the bases for computing retirement percentages by Ingersoll and Luekens et al. differ in two ways: the types of turnover and the categories of teachers included. TFS data show that the turnover of public and private teachers differs greatly, including their reasons for leaving teaching. Therefore, aggregated data (as used by Ingersoll) distorts teacher turnover statistics for both public and private schools. 
NEEDFOR EXPANDED

\section{ANALYSES OF TEACHER TURNOVER}

This brief review of research on teacher turnover has identified a range of issues involving rates of attrition and migration, turnover of SETs versus GETs, attrition rates of beginning teachers, teacher attrition rates versus those in other occupations, and reasons for leaving teaching. Little published research has focused specifically on the turnover of SETs and on differences between the turnover of SETs and GETs, even though the turnover of SETs may be higher or otherwise pose distinctive problems for developing a qualified teaching force in special education. McLeskey (2005) reviewed the limited amount of statistics available on the three types of turnover of SETs and concluded that "These statistics reveal an extraordinarily high level of instability in the special education teaching profession, resulting in teachers moving in and out of special education classrooms at a disquieting rate" (p. xvii). In view of inadequacies in turnover data for SETs, he stated that more recent data and more extensive data are needed on the turnover of SETs - especially on the transfer of SETs to teaching positions in general education (McLeskey, Tyler, \& Flippin, 2004).

Accordingly, this research investigated trends during a recent 9-year period in each of the three types of teacher turnover (attrition, teaching area transfer, migration), separately for SETs and GETs, using national data produced by the TFSs for 1991-1992, 1994-1995, and 2000-2001. These analyses addressed the main issues in turnover reviewed previously and were conducted with TFS data by the same methods to enable valid comparisons among them. All of these original analyses (as opposed to replications of prior published research) extended prior turnover research focused on all public school teachers to studying SETs and GETs separately. Specifically, we investigated the following central research questions:

- What trends occurred in the separate rates of teacher attrition, teaching area transfer, and migration during a recent 9-year period, and to what extent did SETs and GETs differ?

- What trends occurred in the combined rate of teacher turnover (unduplicated sum of at- trition, teaching area transfer, and migration) during a recent 9-year period, and to what extent did SETs and GETs differ?

- How did rates of teacher attrition, teaching area transfer, and migration vary with the number of years of teaching experience, and to what extent did SETs and GETs differ?

- How did the rates of attrition of SETs and GETs compare with rates of attrition in other occupations?

- What were the main reasons for leaving teaching employment, and to what extent did SETs and GETs differ?

\section{METHOD}

\section{DATA SOURCES}

Data sources were teachers' self-reports to three versions of the NCES Schools and Staffing Surveys (SASS; 1990-1991, 1993-1994, and 1999-2000) and to their 1-year longitudinal components, the TFS (1991-1992, 1994-1995, and 2000-2001). The three SASSs were independent, successive cross-sectional surveys. The SASS teacher questionnaires provided national information about public school teachers (including public charter school teachers) during the school year prior to turnover. The TFS provided extensive information about various aspects of the turnover of these teachers.

\section{DEFINITIONS OF SPECIAL AND \\ GENERAL EDUCATION TEACHERS \\ FROM SASS AND TFS}

In keeping with the SASS definition, a teacher was any individual who reported either being employed full time or part time at a public school (including public charter schools) with a main assignment teaching in any Grade(s) $\mathrm{K}-12$, including itinerant teachers and long-term substitutes. Excluded from this definition of a teacher were individuals who identified their main assignment as prekindergarten teacher, short-term substitute, student teacher, teacher aide, or a nonteaching specialist of any kind.

The SASS teacher questionnaires asked teachers to designate one of 64 "main teaching as- 
signment fields" (MTA) as "the field in which you teach the most classes." We grouped these 64 fields into two main areas: special education and general education. Special education included 15 main teaching assignment fields such as deaf and hard-of-hearing, developmentally delayed, and learning disabilities. All teachers who designated one of these 15 fields as their main teaching assignment were defined as SETs. Given that these teacher questionnaires included a category for "other special education," all elementary and secondary teachers with a main assignment in any area of special education should have been able to identify themselves as such, regardless of the particular certification terminology used in their home state. GETs were then defined as all public school teachers $(\mathrm{K}-12)$ other than SETs. Teachers were classified as SETs or GETs based on their MTA during the SASS year prior to turnover.

\section{TEACHER SAMPLES}

The SASS and TFS teacher questionnaires provide nationally representative estimates of the total numbers of public school teachers (full time and part time) based on the teacher sample sizes and response rates shown in Table 1. Sources for these data are found in the 6 references cited below. For completed teacher questionnaires, NCES imputed values for item nonresponse. Choy, Henke, Alt, Medrich, and Bobbitt (1993, Appendix C, for the 1990-1991 SASS); Henke, Choy, Geis, \& Broughman (1996, Appendix C, for the 1993-1994 SASS); and Tourkin et al. (2004, for the 1999-2000 SASS) provide more detailed information about the three SASS administrations. Bobbitt, Leich, Whitener, and Lynch (1994, pp. 19-44, for the 1991-1992 TFS); Whitener et al. (1997, pp. 19-46, for the 1994-1995 TFS); and Luekens et al., (2004, Appendix $B$, for the 2000-2001 TFS) provide more detailed information about the following year TFSs.

\section{DESIGN}

This research was designed to quantify and analyze, from a national perspective, three types of year-to-year turnover of public school teachers in two broad fields: special education in comparison to general education. We analyzed each type of turnover in terms of trends over the three administrations of SASS/TFS (1990-1992, 1993-1995, and 1999-2001). In addition, we examined the relationship of turnover to years of teaching experience, as well as the destination of teachers in the TFS year after turnover from the prior SASS year.

\section{TYPES OF TEACHER TURNOVER}

Below we define three types of teacher turnover from three SASS school years (1990-1991, 1993-1994, and 1999-2000) to the following TFS years. Each type of turnover can be voluntary on the part of a teacher or based on administrative decision (i.e., involuntary on the part of a teacher). In the aggregate, these three SASS years represent the decade of the 1990s.

Attrition. The TFSs provided information about leavers, teachers who left teaching employment following each of the three SASS school years. (Those who continued teaching employment are referred to as continuers.) Leaving teaching employment is called attrition. It is sometimes referred to as exit attrition to distinguish from other forms of attrition such as school attrition (i.e., leaving teaching in a particular school) and teaching area attrition (e.g., leaving a teaching assignment in special education for some other teaching assignment).

Teaching Area Transfer. For teachers continuing teaching employment from one school year to the next, the TFSs provided information about who transferred from one teaching area to a different area (such as from special education to elementary education) following the three SASS years. These teachers are referred to as switchers; teachers who remained in the same teaching area are referred to as remainers. Switching is distinguished from other forms of transfer such as migrating to a different school. Teaching area transfer can co-occur with school migration.

School Migration. For teachers continuing teaching employment from one school year to the next, the TFSs provided information about movers who migrated from one public school to a different school following the three SASS years. Teachers who stayed in the same school are referred to as stayers. 
TABLE 1

Numbers of Completed Public School Teacher Interviews Available for Secondary Analyses From the 1990-1992, 1993-1995, and 1999-2001 SASS/TFS Administrations

\begin{tabular}{|c|c|c|c|c|c|c|c|c|c|}
\hline \multirow[b]{2}{*}{ Teacher Field } & \multicolumn{3}{|c|}{ SASS } & \multicolumn{3}{|c|}{ TFS } & \multicolumn{3}{|c|}{ Turnover ${ }^{a}$} \\
\hline & $\begin{array}{c}\text { School } \\
\text { Year }\end{array}$ & $\begin{array}{l}\text { Teacher } \\
\text { Sample }\end{array}$ & $\begin{array}{c}\text { Response } \\
\text { Rate }^{b}\end{array}$ & $\begin{array}{c}\text { School } \\
\text { Year }\end{array}$ & $\begin{array}{l}\text { Teacherc } \\
\text { Sample }\end{array}$ & $\begin{array}{c}\text { Response } \\
\text { Rated }\end{array}$ & $\begin{array}{l}\text { Leavers } \\
\text { Sample }\end{array}$ & $\begin{array}{c}\text { Switchers } \\
\text { Sample }\end{array}$ & $\begin{array}{l}\text { Movers } \\
\text { Sample }\end{array}$ \\
\hline \multirow[t]{4}{*}{ Special education } & 1990-1991 & 5,054 & & $1991-1992$ & 584 & & 145 & 56 & 175 \\
\hline & 1993-1994 & 5,288 & & $1994-1995$ & 519 & & 156 & 51 & 153 \\
\hline & 1999-2000 & 4,919 & & $2000-2001$ & 518 & & 163 & 50 & 137 \\
\hline & Total & 15,261 & & Total & 1,621 & & 464 & 157 & 465 \\
\hline \multirow[t]{4}{*}{ General education } & 1990-1991 & 41,545 & & $1991-1992$ & 4,156 & & 1,311 & 419 & 888 \\
\hline & 1993-1994 & 41,706 & & 1994-1995 & 3,987 & & 1,569 & 440 & 880 \\
\hline & $1999-2000$ & 39,977 & & $2000-2001$ & 4,580 & & 1,726 & 561 & 1,047 \\
\hline & Total & 123,228 & & Total & 12,723 & & 4,606 & 1,420 & 2,815 \\
\hline \multirow[t]{4}{*}{ Total } & 1990-1991 & 46,599 & $91 \%$ & 1991-1992 & 4,740 & $97 \% / 92 \%$ & 1,456 & 475 & 1,063 \\
\hline & 1993-1994 & 46,994 & $88 \%$ & 1994-1995 & 4,506 & $92 \% / 89 \%$ & 1,725 & 491 & 1,033 \\
\hline & 1999-2000 & 44,896 & $83 \%^{e}$ & $2000-2001$ & 5,098 & $90 \% / 91 \%$ & 1,889 & 611 & 1,184 \\
\hline & Total & 138,489 & & Total & 14,344 & & 5,070 & 1,577 & 3,280 \\
\hline
\end{tabular}

Note. SASS = Schools and Staffing Survey, TFS = Teacher Follow-Up Survey, National Center for Education Statistics, U.S. Department of Education.

${ }^{2}$ Some switchers included in movers, and vice versa. ${ }^{b}$ Weighted response rates for public teachers. Includes stayers, as well as leavers, switchers, and movers.

dWeighted response rates for current teachers/former teachers. ${ }^{e}$ Approximate rate for regular public and charter public combined. 


\section{TEACHING AREA}

Defining teaching areas enables comparisons of teaching area transfer for areas of general education with that for special education. Of the 64 MTAs listed in SASS teacher questionnaires, 15 were in special education with the remaining 49 in general education. A teaching area is a cluster of MTAs that have more in common with each other than they do with MTAs in other areas. Accordingly, we defined special education as 1 teaching area and general education was represented by 11 teaching areas:

1. Special education (such as developmentally delayed, and 14 other specializations)

2. English (English, language arts, journalism, and reading)

3. Mathematics

4. Science (biology, chemistry, earth science, physics, and general science)

5. Social science (social studies or social science, including history)

6. Arts/music (art, dance, drama/theater, and music)

7. Foreign languages (French, German, Latin, Russian, Spanish, and other foreign languages)

8. Physical education and health education

9. Bilingual education and English as a second language

10. Elementary education (including kindergarten)

11. Vocational/business education (accounting, agricultural, business, career, health, etc.)

12. Other general education (home economics, philosophy, architecture, computer science, etc.)

We based this classification of the 64 MTAs into 12 teaching areas on 10 categories NCES devised for this purpose (Seastrom, Gruber, Henke, McGrath, \& Cohen, 2002). We adopted the 10 NCES categories, and added 2 more (vocational education and other general education) in order to classify all 64 MTAs.

Teachers could out-switch at the end of each SASS school year from any one of these teaching areas to any of the other 11 areas during the succeeding TFS year. Likewise, teachers could inswitch from a prior school year to any one of these teaching areas from any of the other 11 areas. It was also possible, of course, for teachers to switch MTAs within a teaching area (such as switching from developmentally delayed to learning disabilities within special education). However, within-area switching was excluded from the definition of "teaching area transfer" for the purposes of this research.

\section{ANALYSIS PROCEDURES}

Based on the samples of public school teachers completing the SASS and TFS teacher questionnaires, we computed national estimates of the weighted numbers of teachers of each type included in the design (along with associated percentages and standard errors) using special procedures developed by NCES for complex sample survey data (Tourkin et al., 2004). Because SASS data are subject to design effects from stratification and clustering of the sample, we computed standard errors for the national estimates and tests of statistical significance by the method of balanced repeated replications with statistical software (WesVar 4.2). We performed chi-square tests of the statistical significance of differences in various turnover percentages on the nationally estimated numbers of teachers, with probability levels based on the sample sizes available for these tests. Logistic regression tested the statistical significance of two predictors (teaching field, TFS year, and the field-by-year interaction) of each of the three types of teacher turnover.

Some of the analyses were performed separately on teacher data from the three administrations of SASS/TFS (1990-1992, 1993-1995, and 1999-2001), whereas other analyses were performed on aggregated teacher data from these three administrations. We used aggregated teacher data to increase sample sizes for several topics, permitting finer grain analyses (with adequate power) of teacher turnover phenomena separately for SETs and GETs that would not have been possible for separate TFS administrations. 


\section{FIGURE 1}

Annual Percentage of Public School Teachers Who Left Teaching Employment in Special Education and General Education, by School Year

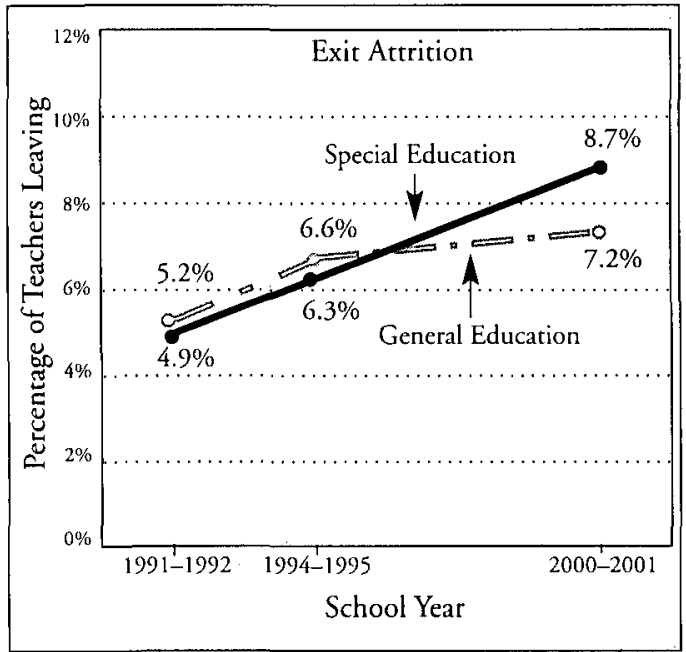

Note. Based on data from the 1991-1992, 1994-1995, and 2000-2001 Teacher Follow-Up Surveys, National Center for Education Statistics, U.S. Department of Education

\section{COMPUTATION OF TURNOVER RATES}

We computed annual rates of the nationally estimated number of public school teachers who left teaching employment, switched teaching area, or migrated to a different school from one school year to the next (e.g., from 1999-2000 to 20002001) as percentages of the total nationally estimated number of public school teachers during the base year (e.g., 1999-2000). Thus, the rates of the three types of teacher turnover (attrition, teaching area transfer, and migration) are directly comparable because they were all computed by the same method.

For computing mean annual rates for each of the three types of turnover during a range of years of teaching experience (e.g., attrition during the 1-3 years of experience), we adopted the procedure used by NCES for attrition (Luekens et al., 2004) and by others (e.g., Ingersoll, 2003). Specifically, the sum of the number of leavers (e.g., from 1999-2000 to 2000-2001) within a range of years of teaching experience (e.g., 1-3) was computed as a percentage of the sum of the number of teachers within the same range of years of teaching experi- ence (e.g., 1-3) during the base year (e.g., 1999-2000). This mean annual attrition rate for a range of years of teaching experience (e.g., 1-3) can be multiplied by the number of years in the range (e.g., 3) to obtain an estimate of the total annual attrition of teachers with that particular range of years of teaching experience.

\section{RESULTS: ATTRITION}

\section{TRENDS IN ATTRITION}

As seen in Figure 1, the annual attrition percentages of both public school SETs and GETs increased steadily and substantially during the 1990 s from a level of about $5 \%$ to $8 \%$. This trend was statistically significant $(p<.001)$, whereas the overall difference in attrition between SETs and GETs was not, nor was the interaction term of year and teaching field. We tested the statistical significance of differences in the attrition percentages of Figure 1 by multivariate models predicting leaving teaching versus continuing in teaching. The predictor variables in the model were TFS year (1991-1992, 1994-1995, and 2000-2001); teaching field (special vs. general education); and year by field interaction term. Teacher attrition in special education appears to be equivalent in magnitude to that in general education during the 1990s.

\section{ATTRITION BY YEARS OF TEACHING EXPERIENCE}

Figure 2 presents average annual attrition percentages by years of teaching experience for full-time and part-time (combined) SETs and GETs; differences between attrition percentages for SETs and GETs across years of teaching experience were statistically significant: $\chi^{2}(3, N=9,927)=25.04$, $p<.001$. Just as other research has shown for all teachers (e.g., Luekens et al., 2004), the highest rate of attrition of early-career SETs and GETs occurred during the first 3 years of experience (with lower and stable rates during the following 6 years). The main differences were that more than twice the annual percentage of SETs (than GETs) with 13 to 24 years of experience left teaching, whereas more GETs (than SETs) left after 24 years of experience. 


\section{F I G URE 2}

Annual Percentage of Public School Teachers in Special and General Education Who Left Teaching Employment, by Years of Teaching Experience



Note. Based on aggregated attrition data from the 1991-1992, 1994-1995, and 2000-2001 Teacher Follow-Up Surveys, National Center for Education Statistics, U.S. Department of Education.

Because the percentage of leavers with 1 to 5 years of teaching experience has been of such interest in the teacher turnover and retention literature, we also computed this quantity with final TFS data for the 2000-2001 TFS. For full-time public school teachers in 1999-2000 with 1 to 5 years of total teaching experience (public and/or private, full time and/or part time), the 5-year attrition percentage was $39.6 \%$; for part-time public school teachers in 1999-2000, this percentage

\section{F I G URE 3}

Annual Corporate Attrition Percentage for Public School Teachers in Special and General Education in Comparison With Other Occupation Fields

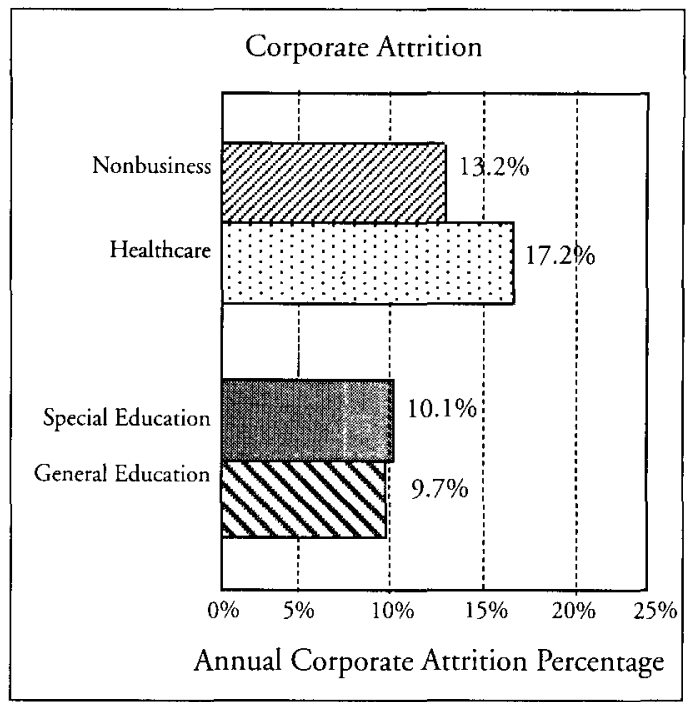

Note. Corporate attrition is defined by leaving an employer, such as a corporation or school district. Percentages shown represent the mean attrition in 1991, 1994, and 2000. Teacher data from Teacher Follow-Up Surveys (National Center for Education Statistics, 2005, U.S. Department of Education. Other occupation data from the Employer Surveys by the Bureau of National Affairs (BNA), Inc.

was 67.4\%; for all public school teachers (full and part time combined), this percentage was $42.2 \%$.

\section{TEACHER ATTRITION COMPARED WITH OTHER OCCUPATIONS}

To examine the possibility that teachers leave at a higher rate than in other vocations, we obtained a type of turnover percentage for other vocations from the only available national data source for calendar years 1991, 1994, and 2000 (BNA, 1992, 1995, 2001). Among the various business and nonbusiness occupations for which BNA reported data, we identified the nonbusiness category (and its subset, health care) as most comparable to the national teaching force. BNA reported turnover at the corporate level; that is, the percentage of employees of corporations who leave their employers annually (excluding departures that are due to reductions in force). For 
public school teachers, this is equivalent to attrition plus the migration of teachers from a local education agency (LEA; i.e., the employing entity) to schools in a different LEA or to private schools. We termed this specific type of turnover corporate attrition. For public school teachers, corporate attrition therefore excludes the migration of teachers among schools within an LEA.

As seen in Figure 3, the annual corporate attrition percentage of SETs and GETs during the 1990 s (aggregated) was comparable (about 10\%), but clearly less than that from all nonbusiness occupations (about 13\%). The average corporate attrition for all employers surveyed by BNA during this time was $12 \%$. In making this comparison, it is important to recognize that BNA corporate attrition data for nonbusiness occupations excluded attrition that was due to reductions in force, whereas the teacher attrition percentage includes a small component that was due to reductions in force. Thus, there is no evidence that public school teachers left their LEA of employment at a higher rate than did employees from nonbusiness employers nationally. In fact, the corporate attrition rate of public teachers was actually lower than for nonbusiness occupations during the $1990 \mathrm{~s}$.

\section{REASONS FOR LEAVING TEACHING}

As shown in Table 2, there is a variety of main reasons given by public school teachers for leaving teaching. To secure sufficient sample size for detailed analyses of this phenomenon, we aggregated attrition data across three TFSs during the 1990s. Even so, the samples for some of the particular reasons for leaving by SETs were small (i.e., less than 30). Therefore, we considered only the subtotals for the five categories of reasons shown in Table 2.

There has been particular concern in the teaching profession that a high percentage of teachers leave (or "escape teaching") because they seek better career opportunities elsewhere or are simply dissatisfied with teaching-rather than leaving for personal reasons, professional development in education, and retirement. Escapees, in particular, have some reason for wanting out of teaching. However, as seen in Table 2, only a minority of teachers leave to escape (about one third of SET leavers and one fourth of GET leavers, a difference that is not statistically significant).

Overall, SETs and GETs do not differ at a statistically significant level in their reasons for leaving teaching. In particular, however, a lower percentage of SETs than GETs left to retire, $16.5 \%$ vs. $28.8 \%$, respectively, a statistically significant difference: $\chi^{2}(1, N=5,035)=5.84$, $p<.02$. This difference is consistent with the smaller percentage of SETs than GETs who left after 24 years of teaching experience $(8.0 \%$ vs. $10.8 \%$, respectively, from Figure 2).

\section{STATUS OF TEACHERS AFTER LEAVING}

Public school teachers who leave teaching employment are not necessarily lost to the profession of education. We analyzed information provided by TFS about the actual status of former teachers the year after leaving. Based on the annual averages for all teachers (i.e., SETs and GETs combined) during the 1990 s, about 58,000 (or 34\%) of 173,000 total leavers assumed nonteaching positions in education, whereas only 13,000 became employed in noneducation occupations. Obviously, massive numbers of public school leavers did not secure better employment opportunities in vocations outside of education. Of the remaining leavers, 41,000 were engaged primarily in homemaking and child care, whereas another 18,000 were retired (many fewer than the 47,000 who gave retirement as the main reason for leaving, as seen in Table 2).

\section{RETURNING TO TEACHING EMPLOYMENT OF EXPERIENCED TEACHERS}

Based on our analysis of aggregated data for the three administrations of SASS/TFS during the 1990 s, approximately 18,500 SETs on average left teaching annually (see Table 2). According to Cook and Boe (in press), during this same period approximately 9,000 experienced teachers (on average) reentered teaching in special education annually from the reserve pool; therefore, the number of reentrants was half that of leavers. Similarly, approximately 152,000 GETs (on average) left teaching annually from 1991-2000 (see Table 2); about 57,000 experienced teachers (on average) reentered teaching in general education from the reserve pool (about $38 \%$ of leavers; 
Main Reasons for Leaving of Exiting Public School Teachers Nationally by Teaching Field (Based on Aggregated Data From the 1991-1992, 1994-1995, and 2000-2001 TFS)

\begin{tabular}{|c|c|c|c|c|}
\hline \multirow[b]{3}{*}{ Main Reason for Leaving ${ }^{a}$} & \multicolumn{4}{|c|}{ Nationally Estimated Leavers Per Year } \\
\hline & \multicolumn{2}{|c|}{ Special Education } & \multicolumn{2}{|c|}{ General Education } \\
\hline & Number & Col. \% & Number & Col. $\%$ \\
\hline \multicolumn{5}{|l|}{ Escape teaching } \\
\hline Other career & 2,698 & 14.5 & 14,164 & 9.3 \\
\hline Better salary & 1,737 & 9.4 & 10,434 & 6.9 \\
\hline Take courses for other career & $226^{b}$ & 1.2 & 1,907 & 1.3 \\
\hline Dissatisfaction with teaching & $2,151^{b}$ & 11.6 & 9,645 & 6.3 \\
\hline Subtotal & 6,812 & 36.7 & 36,150 & 23.8 \\
\hline \multicolumn{5}{|l|}{ Professional development } \\
\hline Take courses for education career & 982 & 5.3 & 8,553 & 5.6 \\
\hline Sabbatical & 438 & 2.4 & 4,891 & 3.2 \\
\hline Subrotal & 1,420 & 7.7 & 13,444 & 8.8 \\
\hline \multicolumn{5}{|l|}{ Personal } \\
\hline Family or personal & 2,589 & 14.0 & 25,630 & 16.9 \\
\hline Pregnancy/child rearing & 3,311 & 17.8 & 18,597 & 12.2 \\
\hline Subtotal & 5,900 & 31.8 & 44,227 & 29.1 \\
\hline \multicolumn{5}{|l|}{ Involuntary } \\
\hline Health & $314^{b}$ & 1.7 & 7,911 & 5.2 \\
\hline Staffing action & $1,034^{\mathrm{b}}$ & 5.6 & 6,513 & 4.3 \\
\hline Subtotal & 1,348 & 7.3 & 14,424 & 9.5 \\
\hline Retirement & 3,060 & 16.5 & 43,727 & 28.8 \\
\hline Total & 18,540 & 100.0 & 151,972 & 100.0 \\
\hline As percentage of total teachers & $6.3 \%$ & & $6.4 \%$ & \\
\hline
\end{tabular}

Note. TFS = Teacher Follow-Up Survey from National Center for Education Statistics, U.S. Department of Education).


than 30 .

Cook \& Boe). Furthermore, our analyses of these aggregated SASS/TFS data during the 1990 s demonstrated only a minority of reentering teachers $(23 \%$ in special education; $15 \%$ in general education) were employed in nonteaching positions in education (Grades $\mathrm{K}-12$ ) during the year prior to reentry. Based on annual averages for SETs and GETs combined, about 58,000 leavers took nonteaching positions in education. However, only 11,000 reentering experienced teachers were employed in such positions during the year prior to reentry. Thus, there has not been massive recy- cling berween teaching and nonteaching positions in $\mathrm{K}-12$ education.

\section{RESULTS: TEACHING AREA TRANSFER}

\section{TRENDS IN TEACHING AREA TRANSFER}

As seen in Figure 4, the annual teaching area transfer percentages of both public school SETs and GETs (to one of 11 other teaching areas) increased steadily and substantially (increases of 


\section{F I G URE 4}

Annual Percentage of Public School Teachers in Special Education and General Education Who Transferred to One of Eleven Teaching Areas, by School Year

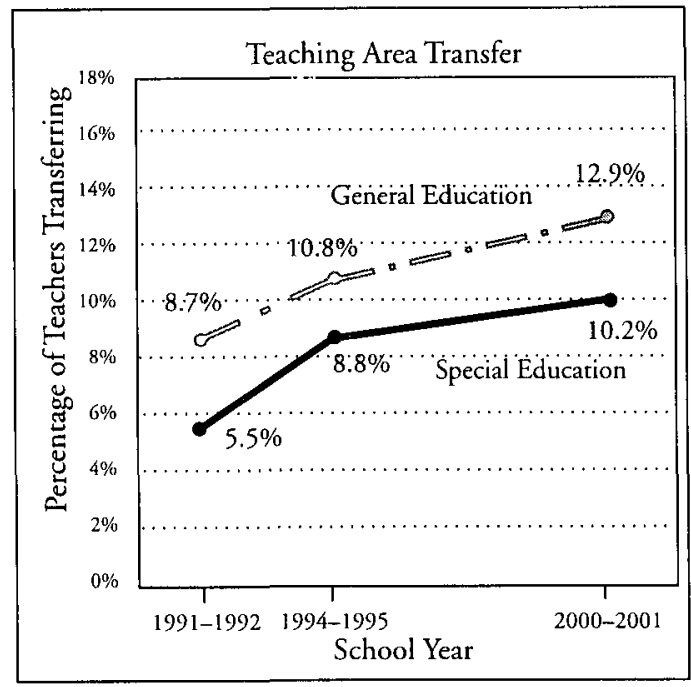

Note. Based on data from the 1991-1992, 1994-1995, and 2000-2001 Teacher Follow-Up Surveys, National Center for Education Statistics, U.S. Department of Education.

about 4 percentage points from 1991-1992 to 2000-2001) during the 1990s. This trend was statistically significant $(p<.001)$, whereas the overall difference in teaching area switching between SETs and GETs was not, nor was the interaction term of year by field. We tested the statistical significance of differences in the switching percentages by multivariate models predicting teachers who switched teaching area versus those who did not switch (including those who left teaching). The predictor variables in the model were TFS year (1991-1992, 1994-1995, and 2000-2001); teaching field (special vs. general education); and year by field interaction term.

This evidence indicates that teaching area switching from special education was equivalent in magnitude to that of general education during the 1990s. In comparing the teaching area switching rates (Figure 4) with the attrition percentages (Figure 1), it is clear that teaching area transfer rates were consistent' $y$ higher than attrition rates for both SETs and GETs. Both kinds of turnover represent losses of teachers to a teaching area. Following the 1999-2000 school year, for example, almost one fifth of teachers $(19 \%)$ were lost to special education either through switching to some other teaching area or through leaving teaching employment. Similar percentage losses of teachers were found for most teaching areas of general education; the large annual turnover of teachers at the teaching area level is characteristic of the teaching profession, not particular to special education.

\section{TEACHING AREA TRANSFER BY YEARS OF TEACHING EXPERIENCE}

As with attrition (see Figure 2), teaching area transfer might be higher for public school teachers during their early career years. Figure 5 shows average annual switching percentages by years of teaching experience for full-time and part-time (combined) SETs and GETs. The differences between switching percentages for SETs and GETs across blocks were statistically significant: $\chi^{2}(2, N$ $=9,927)=10.45, p<.01$. The highest rate of teaching area transfer of SETs occurred during their first 3 years of experience, with gradually and substantially declining rates with increasing years of experience. The teaching area transfer rate of GETs was equivalent to that of SETs during the first 3 years of experience, but (in contrast with SETs) remained at the same level during years 4 to 12 of experience and declined little beyond 12 years of experience. Thus, the higher overall rate of teaching area transfer of GETs (than SETs) seen in Figure 4 can be attributed to that of teachers with more than 3 years of experience.

\section{SPECIAL EDUCATION: TEACHER OUT-SWITCHING AND IN-SWITCHING}

As reported earlier, about half of the attrition of SETs was offset by the reentry of experienced former teachers. A much larger offset occurs with respect to out-switching of teachers from special education. As seen in Figure 6, the out-switching of SETs to general education is equivalent to the simultaneous in-switching of GETs to special education. Although there was an overall trend during the 1990s of an increasing number of teachers switching out of, and into, special education, the apparent stronger increase of in-switching than 


\section{FIGURE 5}

Annual Percentage of Public School Teachers in Special and General Education Who Transferred to One of Eleven Teaching Areas, by Years of Teaching Experience

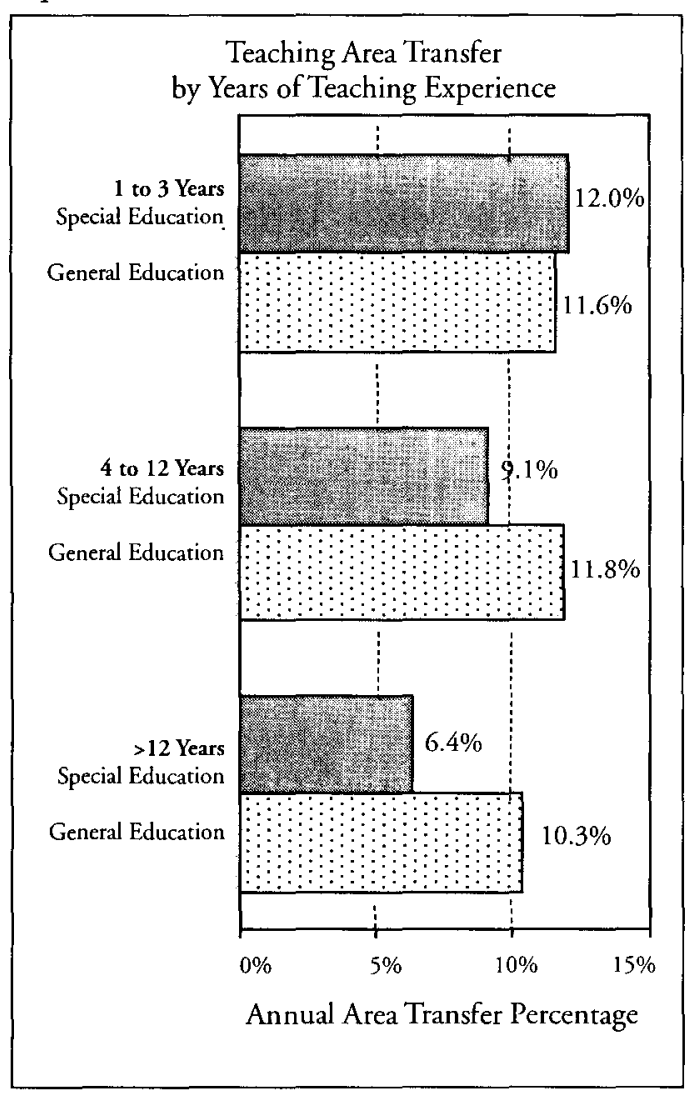

Note. Based on aggregated transfer data from the 1991-1992, 1994-1995, and 2000-2001 Teacher Follow-Up Surveys, National Center for Education Statistics, U.S. Department of Education.

out-switching was not statistically significant. Overall, the out-switchers from special education (73,000 during the 3 years observed) were offset by equivalent numbers of in-switchers from general education $(75,000)$.

Additional analyses demonstrated that $46 \%$ of SET out-switchers went to elementary education, whereas $28 \%$ of in-switchers from general to special education came from elementary education and another $28 \%$ came from language areas (language arts, reading, English, and journalism). The remaining out- and in-switchers were scattered over other teaching areas.

\section{FIGURE 6}

Number of Special Education Teachers Who Transferred to General Education (Out-Switching), and Number of General Education Teachers Who Transferred Into Special Education (In-Switching), by School Year

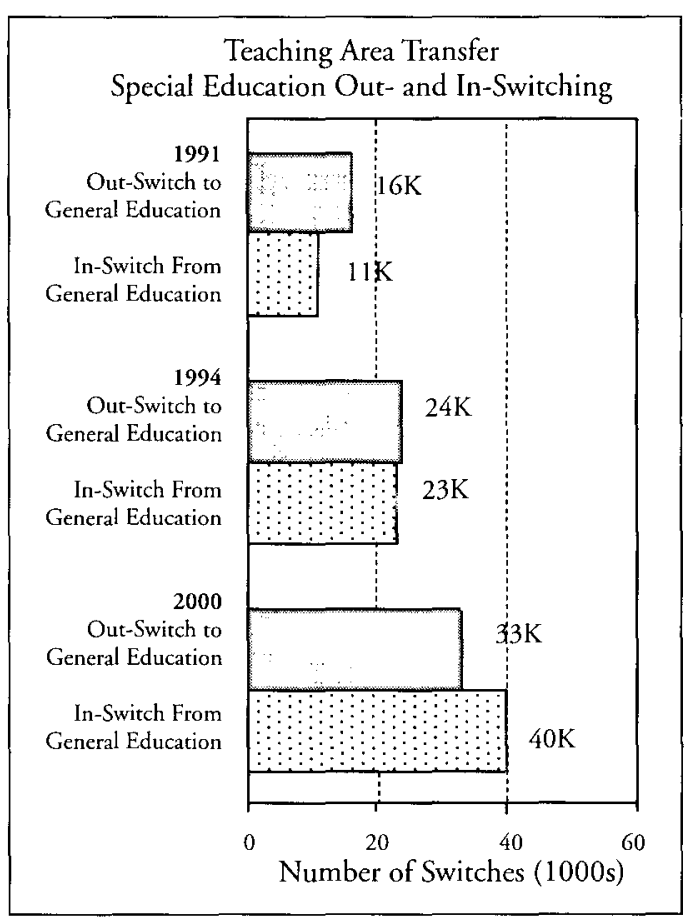

Note. Based on aggregated transfer data from the 1991-1992, 1994-1995, and 2000-2001 Teacher Follow-Up Surveys, National Center for Education Statistics, U.S. Department of Education.

\section{RESULTS: SCHOOL MIGRATION}

\section{TRENDS IN SCHOOL MIGRATION}

As seen in Figure 7, the annual school migration percentages of public school SETs were higher overall during the 1990s than the migration percentages of GETs. This difference was statistically significant $(p<.01)$, whereas year-to-year differences in migration were not, nor was the interaction term of year by teaching field. We tested the statistical significance of differences in these migration percentages by multivariate models predicting teachers who moved to a different school versus those who did not move (including those who left teaching). The predictor variables in the model were TFS year (1991-1992, 1994-1995, 


\section{F I GURE 7}

Annual Percentage of Public School Teachers in Special and General Education Who Migrated to a Different School, by School Year

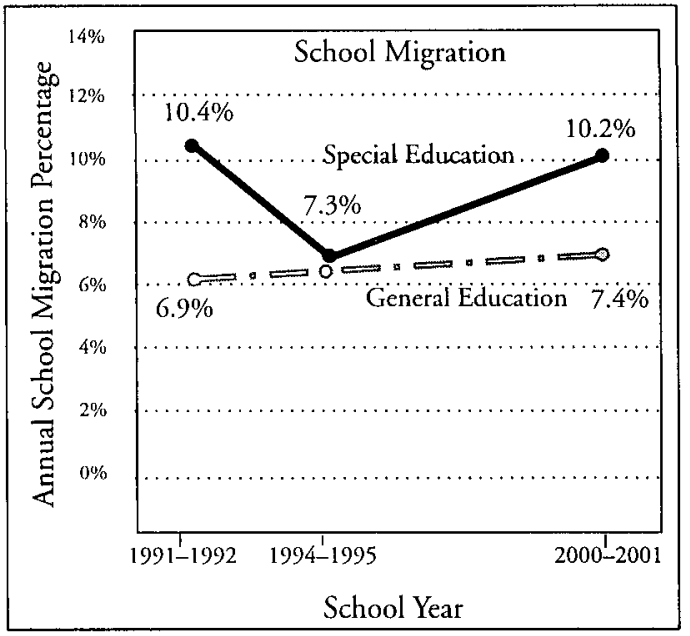

Note. Based on data from the 1991-1992, 1994-1995, and 2000-2001 Teacher Follow-Up Surveys, National Center for Education Statistics, U.S. Department of Education.

and 2000-2001); teaching field (special vs. general education); and year by field interaction term.

These results indicate that the school migration of SETs was higher than that of GETs during the 1990s and higher than both attrition and teaching area transfer. During the 3 years during the 1990s for which TFS turnover data are available, the aggregate turnover percentages for SETs were as follows: $6.7 \%$ for leaving, $8.3 \%$ for switching, and $9.4 \%$ for moving. Because some teachers were both switchers and movers, summing these percentages would yield an overestimate of total turnover.

\section{SCHOOL MIGRATION BY YEARS OF TEACHING EXPERIENCE}

As with attrition and teaching area transfer, school migration might be higher for public school teachers during their early career years (see Figures 2 and 5). Figure 8 shows average annual migration percentages by years of teaching experience for full-time and part-time (combined) SETs and GETs. The differences between school migration percentages for SETs and GETs across blocks

\section{FIGURE 8}

Annual Percentage of Public School Teachers in Special and General Education Who Migrated to a Different School, by Years of Teaching Experience

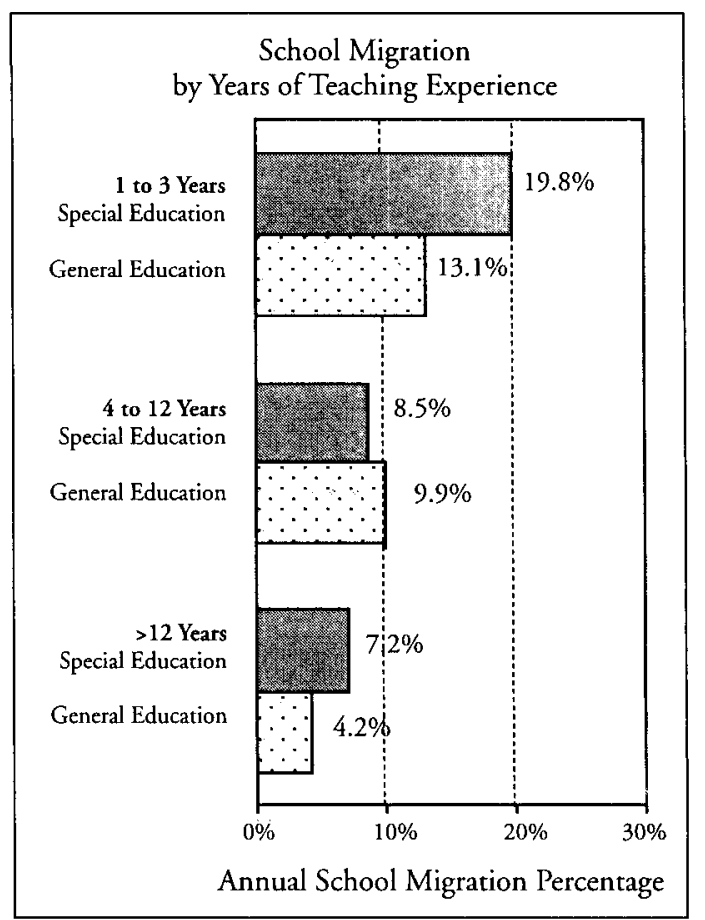

Note. Based on aggregated migration data from the 1991-1992, 1994-1995, and 2000-2001 Teacher Follow-Up Surveys, National Center for Education Statistics, U.S. Department of Education.

were statistically significant: $\chi^{2}(2, N=14,344)=$ $60.31, p<.001$. The highest rate of school migration of both SETs and GETs occurred during their first 3 years of teaching, with gradually and substantially declining rates thereafter. The school migration rate of SETs during the first 3 years was substantially higher than that of GETs, $19.3 \%$ vs. $13.1 \%$, respectively; a statistically significant difference: $\chi^{2}(1, N=3,711)=9.33, p<.01$. Thus, much of the overall higher rate of school migration of SETs seen in Figure 7 can be attributed to that of teachers with 1 to 3 years of experience.

\section{DESTINATION OF SCHOOL MIGRANTS}

Based on aggregated school migration data for the 1990 s, $9.4 \%$ of public school SETs and $7.1 \%$ of GETs migrated from one school to another annually. Of those who moved, more than half 
TABLE 3

School Destinations of Migrating Public School Teachers Nationally by Teaching Field for Three School Years Combined (1991-1992, 1994-1995, and 2000-2001)

\begin{tabular}{llcc}
\hline & & \multicolumn{2}{c}{ Teaching Field $^{a}$} \\
\cline { 3 - 4 } Destination of Movers & \multicolumn{1}{c}{ Statistic } & Special Education & General Education \\
\hline Different school & Column \% & $62.3 \%$ & $52.5 \%$ \\
Same district & (Standard error \%) & $(3.9 \%)$ & $(1.9 \%)$ \\
& National est/year & 17,253 & 89,617 \\
Different district & Column \% & $29.8 \%$ & $34.7 \%$ \\
Same state & (Standard error \%) & $(3.3 \%)$ & $(1.8 \%)$ \\
Nut-of-state district & Column \% & 8,239 & 59,126 \\
& (Standard error \%) & $4.2 \%$ & $9.0 \%$ \\
Private school & National est/year & $(0.9 \%)$ & $(1.2 \%)$ \\
& Column \% & 1,149 & 15,382 \\
& (Standard error \%) & $3.7 \% \mathrm{c}$ & $3.8 \%$ \\
Mover total & National est/year & $(3.0 \%)$ & $(0.7 \%)$ \\
& National est/year & 1,037 & 6,502 \\
& Column \% & 27,678 & 170,627 \\
& & $100.0 \%$ & $100.0 \%$
\end{tabular}

Note. Based on aggregated data from the 1991-1992, 1994-1995, and 2000-2001 Teacher Follow-Up Surveys, National Center for Education Statistics, U.S. Department of Education.

${ }^{a}$ The destination of movers by teaching field $(4 \times 2) \chi^{2}$ was $4.40(p>0.05)$. ${ }^{b}$ Nationally weighted estimates per year (est/year) of the total numbers of full-time and part-time teachers combined at both the elementary and secondary levels in the public sector. 'Sample size ( $n$ ) less than 30.

migrated to schools within the same LEA $(62.3 \%$ of SETs; $52.5 \%$ of GETs; see Table 3). Slightly more than half of within-LEA migration was involuntary on the part of teachers; it was reassignment by administrative decision (Boe, Barkanic, \& Leow, 1999). Most other movers went to other LEAs in the same state $(29.8 \%$ of SETs; $34.7 \%$ of GETs); the remaining small percentage of movers went out of state or to private schools.

\section{RESULTS: ATTRITION, TRANSFER, AND MIGRATION COMBINED}

As seen in Figure 9, the total annual turnover (the sum of attrition, teaching area transfer, and school migration) of SETs and GETs increased substantially during the 9-year period from 1991-1992 to $2000-2001$. Turnover increased $60 \%$ for all public teachers (from 478,000 to 767,000 annually). These total turnover numbers are unduplicated counts; teachers who both switched teaching area and moved to a different school are counted only once.

Some of this increase in teacher turnover might be expected because the teaching force grew during these years. However, the rate of total turnover for all public teachers likewise increased substantially (from $18.8 \%$ in 1991-1992 to $25.62 \%$ in $2000-2001$, a $36 \%$ increase). Moreover, the number of teachers turning over per public school increased from 5.66 in 1991-1992 to 8.34 in $2000-2001-a$ 47\% increase.

Based on aggregated data for 1991-1992, 1994-1995, and 2000-2001, the total annual turnover of public school teachers was virtually identical for SETs and GETs $(22.8 \%$ and $22.4 \%$, respectively). Table 4 shows the magnitude of in- 


\section{FIGURE 9}

Annual Total Turnover of Public School Teachers in Special and General Education (Attrition, Teaching Area Transfer, and School Migration Combined) Based on Unduplicated Counts of Teachers

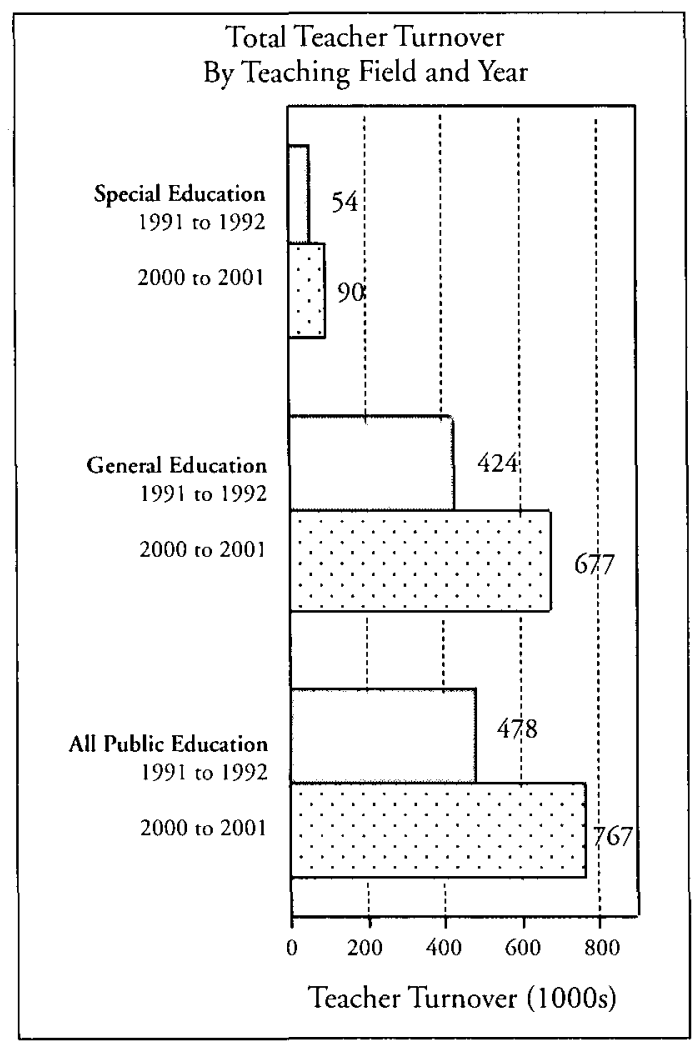

Note. Based on data from the 1991-1992 and 2000-2001 Teacher Follow-Up Surveys, National Center for Education Statistics, U.S. Department of Education.

dependent components of teacher turnover. Attrition only accounted for about $30 \%$ of total turnover; the substantial majority of turnover lies within the ranks of employed teachers. Although this poses problems for staffing the schools and reaching areas from which teachers depart, it contributes to solving staffing problems for the schools and teaching areas that such teachers enter. At least turnover within the national teaching force does not require replacement teachers to be recruited from outside the force.

As seen in Table 4, there were some differences between SETs and GETs in the extent of various types of turnover. SETs were somewhat less likely to switch teaching areas than GETs, whereas SETs were somewhat more likely to move to a different school than GETs. Considering the extent of differences in all components of turnover, however, special education and general education were more similar than different.

Nonetheless, almost one of every four specific teaching positions in both special and general education was subject to annual turnover during the 1990s. That is, as positions became open through the departure of incumbent teachers, they were filled with different teachers (assuming these open positions were not left vacant or discontinued-rare events according to Henke, Choy, Chen, et al., 1997). This degree of instability in the teaching staff of individual schools represents a serious problem that educational administrators must, and do, solve each year.

\section{DISCUSSION}

Clearly, teacher turnover has been high nationally as 22 to $23 \%$ of public SETs and GETs either left teaching, switched teaching area, or migrated to a different school annually during the 1990s. This level of turnover is even higher than reported elsewhere (e.g., Ingersoll, 2003) because we included teaching area transfer as part of turnover along with attrition and migration. Not only is the rate of overall teacher turnover high, but it actually increased by more than a third during the 9 years from 1991-1992 to 2000-2001 because of growth in the rates of attrition and teaching area transfer. The field of education has allowed this to happen even though it has been recognized that teacher turnover is costly in terms of student achievement, school functioning, and financial expenditures (see Johnson et al., 2005). Of course, the impact of teacher turnover must be, has been, and no doubt will be managed every year by our public school systems. Its costs will continue to be paid, however, unless better ways to reduce teacher turnover are devised and implemented to scale.

We recognize that some initiatives to reduce the high and increasing rates of teacher turnover have been effective at the state and local levels. However, the cumulative effects of these initiatives have not been sufficient to halt the steady growth of turnover at the national level. The 
TABLE 4

Turnover Components for Public School Teachers Nationally by Teaching Field for

Three School Years Combined (1991-1992, 1994-1995, and 2000-2001)

\begin{tabular}{|c|c|c|c|}
\hline \multirow[b]{2}{*}{ Destination of Movers } & \multirow[b]{2}{*}{ Statistic ${ }^{b}$} & \multicolumn{2}{|c|}{ Teaching Field ${ }^{a}$} \\
\hline & & Special Education & General Education \\
\hline \multirow[t]{3}{*}{ Attrition } & Column \% & $29.5 \%$ & $28.4 \%$ \\
\hline & (Standard error \%) & $(3.0 \%)$ & $(0.8 \%)$ \\
\hline & National est/year & 19,922 & 153,009 \\
\hline \multicolumn{4}{|l|}{ Teaching area transfer } \\
\hline \multirow[t]{3}{*}{ Stay at same school } & Column \% & $29.6 \%$ & $39.8 \%$ \\
\hline & (Standard error \%) & $(3.2 \%)$ & $(1.1 \%)$ \\
\hline & National est/year & 19,979 & 214,239 \\
\hline \multirow[t]{3}{*}{ Move to different school } & Column \% & $6.6 \%{ }^{\mathrm{c}}$ & $9.0 \%$ \\
\hline & (Standard error \%) & $(1.1 \%)$ & $(0.7 \%)$ \\
\hline & National est/year & 4,470 & 48,277 \\
\hline \multirow[t]{3}{*}{ Subtotal } & Column \% & $36.2 \%$ & $48.8 \%$ \\
\hline & (Standard error \%) & $(3.2 \%)$ & $(1.2 \%)$ \\
\hline & National est/year & 24,449 & 262,516 \\
\hline \multicolumn{4}{|l|}{ Move to different school, } \\
\hline \multirow[t]{3}{*}{ Remain at same teaching area } & Column \% & $34.3 \%$ & $22.8 \%$ \\
\hline & (Standard error \%) & $(2.3 \%)$ & $(0.9 \%)$ \\
\hline & National est/year & 23,209 & 122,495 \\
\hline \multirow[t]{2}{*}{ Total turnover } & National est/year & 67,580 & 538,020 \\
\hline & Column $\%$ & $100.0 \%$ & $100.0 \%$ \\
\hline
\end{tabular}

Note. Based on aggregated data from the 1991-1992, 1994-1995, and 2000-2001 Teacher Follow-Up Surveys, National Center for Education Statistics, U.S. Department of Education.

${ }^{a}$ The four turnover components by teaching field $(4 \times 2) \chi^{2}$ was $25.28(p<0.01)$. ${ }^{b}$ Nationally weighted estimates per year (est/year) of the total numbers of full-time and part-time teachers combined at both the elementary and

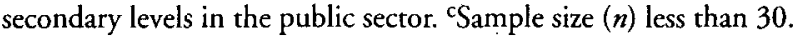

turnover of teachers in public schools has been costly to the field and a significant contributor to the shortage of qualified teachers in both special and general education. There are three main approaches to dealing with these problems: (a) initiate renewed efforts to reduce each of the three types of turnover, (b) improve the management of the costs of teacher turnover, and (c) increase the supply of qualified teachers-all of which are discussed in the following.

\section{ATTRITION}

Our analyses of teacher attrition are relevant to the issues of whether teacher shortages are mostly due to excessive attrition or to inadequate supply and whether the most promising response to teacher shortages is expanded efforts to increase the retention of employed teachers or, instead, to increase the supply of qualified teachers. According to Ingersoll (2001) and NCTAF (2003), excessive attrition (therefore, inadequate retention) is the crux of the teacher shortage problem because excessive attrition creates high demand for entering teachers. In this view, teacher supply would be sufficient (except in several subjects) if it were not for such high demand that is due to attrition.

The results of our research do not support this view. Instead, the evidence presented here 
suggests that teacher attrition has not been excessive in comparison with other vocations. The attrition of both public school SETs and GETs was less than that in nonbusiness occupations (and its health care component) during the 1990s. In addition, Henke, Zahn, and Carroll (2001) found that the attrition of public and private teachers (combined), during their first 3 years, was among the lowest of several occupations studied. Thus, teaching seems to be a reasonably appealing occupation in comparison with others. If teaching were relatively unattractive, initiatives to improve retention would have more promise of success. Consequently, the most promising approach to reduce teacher shortages is to increase the supply of qualified teachers.

Furthermore, the perception that the teaching profession "eats its young" (e.g., Halford, 1998) is not supported by our findings, even though beginning teachers leave at a somewhat higher rate than experienced teachers before retirement age. Across four TFSs from 1988-1989 to 2000-2001, Luekens et al. (2004) found that attrition was only about $2 \%$ higher for public teachers with 1 to 3 years of full-time teaching experience than with 4 to 9 years. We found a similar difference for SETs and GETs separately, with data from the three most recent TFSs. These higher rates are concentrated in the first 3 years of teaching, not the first 5 years. By Years 4 and 5, the attrition rates decline to the overall level seen for teachers with 4 to 9 years of experience (Boe, Cook, \& Sunderland, 2005). A somewhat higher rate of attrition for beginning teachers should be expected as they assess the fit of their qualifications and interests to the demands of classroom teaching. As others have noted as well, some beginning teachers are lacking in these respects and should leave (e.g., Johnson et al., 2005; NCES, 2005).

The results of our research also indicate that that there is limited potential for policy initiatives and improvements in practice to reduce the attrition of qualified teachers in public schools. Only about one quarter of teacher attrition in general education (and one third in special education) is due mainly to teachers who seek better opportunities in other vocations or who are otherwise dissatisfied with teaching. It is reasonable to expect that dramatic improvements in induction pro- grams, working conditions, administrative support, and salaries would reduce the attrition of a sizable percentage of this group. But such workplace improvements would likely have only a modest impact on the majority of teachers who leave (i.e., those who leave for personal reasons, poor health, job actions, and retirement).

Thus, the results of our research for both public SETs and GETs do not support NCTAF's (2003) perspective that inadequate teacher retention has become a national crisis. Instead, retention seems to have been as high as might reasonably be expected under prevailing conditions. Substantial improvement in teacher retention would require massive systemic changes in the culture of public schooling and even greater allocation of public funds. In spite of enormous efforts to improve public education during the past 2 decades, teacher attrition has increased. Given this, it is unrealistic to expect a level of sustained national commitment of sufficient scope to reduce substantially teacher attrition. Even containing its growth will be difficult. The implication is that it will be more productive for the field of education to make shrewd investments in increasing teacher supply than in reducing attrition.

\section{It is unrealistic to expect a level of} sustained national commitment of sufficient scope to reduce substantially teacher attrition. Even containing its growth will be difficult.

In these respects, the attrition component of teacher turnover is quite different than teaching area transfer and school migration in that only about a quarter of attrition is mainly job-related (most is for personal reasons and retirement), whereas transfer and migration are largely due to job-related considerations. Consequently, there may be more potential for educational policy interventions to reduce transfer and migration.

\section{TEACHING AREA TRANSFER}

Even though teaching area transfer (one type of turnover) poses serious problems for staffing schools, its study with large-scale national data 
has been neglected. Our results demonstrate that a somewhat higher percentage of SETs transfer to teaching assignments in general education than leave teaching employment. However, teaching area transfer is characteristic of the entire teaching force. Because both SETs and GETs transferred among teaching areas at comparable rates, teaching area transfer of SETs was not excessive by comparison. Without more information, it is not possible to determine whether the rate of teaching area transfer of GETs has been excessive. In spite of initiatives that may have been made to reduce teaching area transfer, our results show it has been an enduring and increasing phenomenon.

Although the annual rates of teaching area transfer were high for both SETs and GETs (more than $10 \%$ in 2000-2001), the number of teachers transferring between special and general education was not significantly different. Thus, there was no net loss (or gain) to special education in the number of teachers transferring berween these two broad fields.

There is some evidence from state-level data as to why SETs switch to teaching assignments in general education. One reason is that some beginning SETs, who were prepared to teach in general education, later found a teaching position for which they were more qualified (Schrag \& Theobald, 1989). Other research indicates that SETs switch to general education because of high stress and insufficient administrative support (Billingsley \& Cross, 1991). Unfortunately, TFS did not collect information nationally from SETs about their main reason for transferring to general education or from GETs about their main reason for transferring among teaching areas.

These findings suggest some potential for reducing the out-switching of SETs. First, improvement is clearly needed in the numbers of individuals prepared for teaching in special education. No doubt because the supply of such individuals was insufficient, $18 \%$ of first-time teachers hired into special education in 1999-2000 had been prepared for teaching in general education (Cook \& Boe, in press). Likewise, stress reduction and improvement in the administrative support for SETs may be possible, as advocated by Kozleski et al. (2000). Nonetheless, as shown here, the national rates of teaching area transfer for both SETs and GETs increased rapidly during a recent decade. Consequently, it is unrealistic to expect interventions of sufficient national scope to reduce substantially teaching area transfer. Containing its growth will be a challenge.

\section{SCHOOL MIGRATION}

As we have shown, SETs moved to a different school at a significantly higher rate than GETs (10.2\% vs. $7.4 \%$, in $2000-2001)$. In this comparison, the migration of SETs appears to have been excessive. Without more information, however, it is not possible to determine whether the migration rate of GETs was excessive. Nonetheless, a mover is just as costly to a school as a leaver is even though school migration does not represent a loss to the national teaching force (e.g., Ingersoll, 2001).

Unfortunately, we do not have specific information to report on the reasons for SET migration. From this research, we have shown that more than half the amount of school migration of both SETs and GETs occurred between schools within the same school district. In prior national research based on all public school teachers, the main reason for within-district migration was involuntary on the part of teachers (i.e., $51 \%$ was due to school staffing actions; Boe et al., 1999). Thus, education administrators are responsible for a considerable amount of migration.

Based on TFS data for 2000-2001, Luekens et al. (2004) computed the percentage of all public school teachers who rated various reasons for moving as very important or extremely important. By far, the two most important reasons (reported by about $40 \%$ of movers) were opportunity for a better teaching assignment (subject area or grade level) and dissatisfaction with administrative support at the previous school.

Even though the major factors driving school migration (staffing actions, unfavorable teaching assignments, and inadequate administrative support) are subject to administrative interventions, migration held steady at a fairly high level during the 1990s. Either interventions intended to reduce migration have not been successful or policy makers have not initiated such interventions. Consequently, it is not realistic to expect that the management of public education will be im- 
proved sufficiently in the foreseeable future to reduce teacher migration substantially.

\section{MANAGING TURNOVER}

We recognize that high teacher turnover has been a costly and enduring problem. It should continue to be the subject of research and policy attention with a view to identifying feasible practices that will improve retention. Nonetheless, turnover is endemic to public education as currently organized. So long as this continues, other approaches to reducing the costs of turnover should be designed and implemented. One of these is to improve the management of turnover. With about one in four teaching assignments turning over every year as the national average, the task of managing these transitions is enormous.

In managing turnover, it should be recognized that a substantial majority of individuals involved are experienced teachers instead of firsttime teachers. All teachers switching teaching areas and moving to a different school have teaching experience, as do half of new entrants into public school teaching (the other half are firsttime teachers; Cook \& Boe, in press). Thus, of the total annual turnover reported here, about $85 \%$ of teachers involved have teaching experience. Managing the costs of turnover, therefore, should be focused on issues associated with the turnover of experienced teachers-especially the $70 \%$ of annual turnover represented by teaching area transfer and school migration.

One cost of teacher turnover is organizational-a cost that can be managed by school personnel. With respect to teachers new to their assignment, it is important to minimize disruption in instructional programs by providing them with the perspectives, knowledge, and skills required to sustain the effective functioning of ongoing school programs and to integrate them into the faculty by opening lines of communication and building cohesion (e.g., Johnson et al, 2005).

To accomplish this, schools might reduce the organizational costs of turnover by offering more varied and extensive induction programs tailored to a variety of specific circumstances. Induction programs currently exist particularly for individuals beginning their first year of teaching; these should be retained and improved as needed. In addition, different kinds of induction programs should be designed and provided for the major influx of experienced teachers into open positions, that is, for those reentering teaching employment, moving from different schools, and switching teaching assignments (e.g., from general to special education).

Another approach to reducing the organizational costs of turnover is more standardization of curriculum and instruction. The greater the similarity between a teacher's training/experience and the requirements of a new teaching assignment, the easier it will be for the teacher to perform effectively. Although most schools will insist on retaining the freedom to innovate and to design programs tailored to local needs, a consequence will continue to be difficulties in inducting a substantial percentage of new teachers annually.

Another cost of teacher turnover is financial. As reviewed by Johnson et al. (2005), estimates of turnover costs vary widely and depend on many variables. The conclusion is inescapable, nonetheless, that the financial cost of the three types of turnover is enormous nationally. Based on U.S. Department of Labor turnover cost estimates, the Alliance for Excellent Education (2005) computed replacement costs of about $\$ 4.9$ billion annually for teachers who leave teaching employment and who move to another school. Whatever the huge financial cost of teacher turnover, it must be paid. The development of more financially efficient methods for managing teacher turnover represents an important objective for education policy makers, executives, and researchers.

\section{TEACHER SUPPLY}

Another approach to the costs of teacher turnover is to increase the supply of qualified teachers. The national shortage of qualified teachers in many teaching areas is due either to excessive demand from attrition or to insufficient supply or both. Our conclusions from this research are that teacher attrition is not excessive in comparison with other vocations and that retention will not improve substantially unless prevailing conditions improve dramatically. This is unlikely; therefore, 
the supply of qualified teachers needs to be increased sufficiently to satisfy demand.

Although the topic of teacher supply is too large and complex to be reviewed here (see Cook $\&$ Boe, in press; Curran \& Abrahams, 2000; NCES, 2005), we use special education to illustrate the need for enhanced supply. Of first-time SETs hired in 1999-2000, only $46 \%$ were extensively prepared to teach in special education; the others were either prepared in general education or had inadequate preparation (Cook \& Boe). It is not surprising that inadequate supply increases turnover as many SETs switch to assignments in general education for which they prepared.

\section{BENEFITS OF TURNOVER}

Although the costs of teacher turnover are a major concern, the benefits of teacher turnover should also be recognized and better understood. Unfortunately, these benefits are a neglected area of research. Our results, however, document some benefits. Of SETs who leave each year, about half are replaced by returning experienced teachers (for GETs, about 38\%). This is indeed a "revolving door," but the fact that so many former teachers return is a major asset to the field. Nonetheless, teacher turnover still entails costs, but the costs for training more first-time teachers would be even higher were it not for returning experienced teachers.

In addition, much of the attrition of teachers is an asset to the field of education because about one third of leavers became employed in nonteaching positions in education. As we have shown, more than four times as many leavers became employed in nonteaching positions in education the year after leaving than became employed in other vocations.

A somewhat higher rate of attrition of teachers during their first 3 years of experience is not surprising, and some is probably constructive. New teachers explore the fit of their interests and qualifications for the demands of the profession. Not all are suited; hence, these should leave (Johnson et al., 2005; NCES, 2005; NCTAF, 2003). And as Wayne (2000) concluded, only one quarter of beginning teachers leave to pursue other careers or because of dissatisfaction. Given these considerations, the somewhat higher rate of attrition for public school teachers with 1 to 3 years of experience is not alarming and some of it is constructive.

\section{RESEARCH IMPLICATIONS}

Compared with the extensive analysis of teacher attrition and the reasons causing it, reported here and elsewhere, much more research should be devoted to understanding the reasons for teaching area transfer and school migration and for interventions that improve the retention of qualified teachers. In addition, a much better empirical understanding of the costs and benefits of teacher turnover will be useful in assessing tradeoffs and targeting interventions.

TFS data on teacher turnover represent a 1year change. To supplement this, more research with long-range longitudinal data such as from the 10 -year $B \& B$ study is needed to provide more detailed and precise information about turnover phenomena.

\section{LIMITATIONS}

Because our results are based on large national probability samples of public school teachers, they should not be interpreted as directly applicable to the state or local levels unless supported by other data from the relevant level. For example, attrition of SETs might be greater in urban than suburban school districts - another topic for further research. Other than the behavioral definitions of teacher attrition and school migration by TFS, SASS and TFS data are from teacher self-reports and therefore subject to errors of recall and bias. As with all sample data such as SASS, the estimates reported are subject to sampling error as well as to measurement and recording error. All estimates should therefore be interpreted as approximate.

\section{CONCLUSIONS}

A high rate of annual teacher turnover has been an enduring aspect of the teaching profession and will almost certainly remain so in the foreseeable future withour dramatic improvements in the organization, management, and funding of public schools. Until then, an increased supply of quali- 
fied teachers is needed to reduce teacher shortages created in large part by teacher turnover. In addition, the field of education should improve its understanding of the costs and benefits of turnover and improve its management of turnover in order to reduce its costs and enhance its benefits.

We recognize that rates of teacher turnover are exceptionally high in some teaching areas and types of schools (Guarino et al., 2006) where interventions intended to improve retention might well be effective and beneficial even though having minimal impact on aggregate national rates. Fortunately, measures taken to improve teacher retention (e.g., better working conditions and higher salaries) will also make the teaching profession more attractive as a career choice and, therefore, will likely serve to increase teacher supply.

\section{REFERENCES}

Alliance for Excellent Education. (2005). Teacher attrition: A costly loss to the nation and to the states (Issue Brief). Washington, DC: Author.

Billingsley, B. S. (2004). Special education teacher retention and attrition: A critical analysis of the research literature. The Journal of Special Education, 38, 39-55.

Billingsley, B. S. (2005). Cultivating and keeping committed special education teachers: What principals and district leaders can do. Thousand Oaks, CA: Corwin Press.

Billingsley, B. S., \& Cross, L. H. (1991). Teachers' decisions to transfer from special to general education. The Journal of Special Education, 24, 496-511.

Bobbitt, S. A., Leich, M. C., Whitener, S. D., \& Lynch, H. F. (1994). Characteristics of stayers, movers, and leavers: Results from the Teacher Followup Survey, 1991-92 (NCES Publication No. 94-337). Washington, DC: National Center for Education Statistics, U.S. Department of Education.

Boe, E. E., Barkanic, G., \& Leow, C. S. (1999). Retention and attrition of teachers at the school level: National trends and predictors (Data Analysis Rep. No. 1999DAR1). Philadelphia: University of Pennsylvania Graduate School of Education, Center for Research and Evaluation in Social Policy. (ERIC Document Reproduction Service No. ED436485)

Boe, E. E., Bobbitt, S. A., Cook, L. H., \& Barkanic, G. (1998). National trends in teacher supply and turnover for special and general education (Data Analysis Rep. No. 1998-DAR1). Philadelphia: University of Pennsyl- vania Graduate School of Education, Center for Research and Evaluation in Social Policy. (ERIC Document Reproduction Service No. ED426549)

Boe, E. E., Cook, L. H., \& Sunderland, R. J. (2005, July). Turnover of special education teachers: New research on the extent and impact of exit attrition, transfer to general education, and school transfer. Paper presented at the 2005 OSEP Project Directors Conference, Washington, DC.

Boe, E. E., \& Gilford, D. M. (Eds.) (1992). Teacher supply, demand, and quality: Policy issues, models, and data bases. Washington, DC: National Academy Press.

Bureau of National Affairs. (1992). BNA's quarterly report on job absence and turnover: 4th quarter 1991. Bulletin to Management (March 12). Washington, DC: Author.

Bureau of National Affairs. (1995). BNA's quarterly report on job absence and turnover: 4th quarter 1994. Bulletin to Management (March 9). Washington, DC: Author.

Bureau of National Affairs. (1999). BNA's quarterly report on job absence and turnover: 4th quarter 1998. Bulletin to Management (Vol. 50, No. 10, Part II). Washington, DC: Author.

Bureau of National Affairs. (2000). Job absence \& turnover: 4th quarter 1999. Bulletin to Management (Vol. 51, No. 10, Part II). Washington, DC: Author.

Bureau of National Affairs. (2001). Job absence \& turnover: 4th quarter 2000. Bulletin to Management (Vol. 52, No. 10, Part II). Washington, DC: Author.

Bureau of National Affairs. (2002). Job absence \& turnover: 4th quarter 2001. Bulletin to Management (Vol. 53, No. 11, Part II). Washington, DC: Author.

Center on Education Policy. (2006). Basic (and sometimes surprising) facts about the U.S. education system: $A$ public education primer. Washington, DC: Author.

Choy, S. P., Henke, R. R., Alt, M. N., Medrich, E. A., \& Bobbitt, S. A. (1993). Schools and staffing in the United States: A statistical profile, 1990-91. Washington, DC: National Center for Education Statistics, U.S. Department of Education.

Cook, L. H., \& Boe, E. E. (in press). National trends in the sources of supply of teachers in special and general education. Teacher Education and Special Education.

Curran, B., \& Abrahams, C. (2000, January). Teacher supply and demand: Is there a shortage? (Issue Brief). Retrieved July 3, 2003, from http://www.nga.org/cda/ files/000125TEACHERS.pdf

Guarino, C. M., Santibañez, L., \& Daley, G. A. (2006). Teacher recruitment and retention: $A$ review of 
the recent empirical literature. Review of Educational Research, 76, 173-208.

Halford, J. (1998). Easing the way for new teachers. Educational Leadership, 55(5), 33-36.

Hanushek, E. A., Kain, J. G., \& Rivkin, S. G. (2004). The revolving door: Factors affecting teacher turnover. In W. J. Fowler, Jr. (Ed.), Developments in school finance, 2013: Fiscal proceedings from the annual state data conference of July 2003 (pp. 5-15). Washington, DC: National Center for Education Statistics, U.S. Department of Education.

Henke, R. R., Chen, X., Geis, S., \& Knepper, P. (2000). Progress through the teacher pipeline: 1992-93 college graduates and elementary/secondary school teaching as of 1997. Washington, DC: National Center for Education Statistics, U.S. Department of Education.

Henke, R. R., Choy, S. P., Chen, X., Geis, S., Alt, M. N., \& Broughman, S. P. (1997). America's teachers: Profile of a profession, 1993-94. Washington, DC: National Center for Education Statistics, U.S. Department of Education.

Henke, R. R., Choy, S. P., Geis, S., \& Broughman, S. P. (1996). Schools and staffing in the United States: A statistical profile, 1993-94. Washington, DC: National Center for Education Statistics, U.S. Department of Education.

Henke, R. R., Zahn, L., \& Carroll, C. D. (2001). Attrition of new teachers among recent college graduates: Comparing occupational stability among 1992-93 graduates who taught and those who worked in other occupations. Washington, DC: National Center for Education Statistics, U.S. Department of Education.

Ingersoll, R. M. (1997). Teacher turnover and teacher quality: The recurring myth of teacher shortages. Teachers College Record, 91(1), 41-44.

Ingersoll, R. M. (2001). Teacher turnover and teacher shortages: An organizational analysis. American Educational Research Journal, 38, 499-534.

Ingersoll, R. M. (2002). The teacher shortage: A case of wrong diagnosis and wrong prescription. NASSP Bulletin, 86(631), 16-31.

Ingersoll, R. M. (2003). Is there really a teacher shortage? A research report (Document No. R-03-4). Seattle: University of Washington, Center for the Study of Teaching and Policy.

Johnson, S. M., Berg, J. H., \& Donaldson, M. L. (2005). Who stays in teaching and why? A review of the literature on teacher retention. Cambridge, MA: Harvard Graduate School of Education.

Kozleski, E., Mainzer, R., Deshler, D., \& Coleman, M. R. (2000). Bright futures for exceptional learners: An ac- tion agenda to achieve quality conditions for teaching and learning. Reston, VA: Council for Exceptional Children.

Luekens, M. T., Lyter, D. M., \& Fox, E. E. (2004). Teacher attrition and mobility: Results from the Teacher Follow-up Survey, 2000-01 (NCES Publication No. 2004-301). Washington, DC: National Center for Education Statistics, U.S. Department of Education.

McLeskey, J. (2005). Forward. In B. S. Billingsley, Cultivating and keeping committed special education teachers: What principals and district leaders can do (pp. xvi-xix). Thousand Oaks, CA: Corwin Press.

McLeskey, J., Tyler, N. C., \& Flippin, S. S. (2004). The supply and demand for special education teachers: A review of research regarding the chronic shortage of special education teachers. The Journal of Special Education, 38, 5-21.

National Center for Education Statistics. (2005). The condition of education 2005 (NCES Publication No. 2005-094). Washington, DC: National Center for Education Statistics, U.S. Department of Education.

National Commission on Teaching and America's Future. (2003). No dream denied: A pledge to America's children. New York: Author.

Podgursky, M. (2006). Is there a "qualified teacher" shortage? Education Next, 6(2), 27-32.

Schrag, J. A., \& Theobald, N. D. (1989). The adequacy of current and projected special education personnel supply in Washington state. Olympia, WA: Office of the Superintendent of Public Instruction, Division of Special Services and Support Programs.

Seastrom, M. M., Gruber, K. J., Henke, R., McGrath, D. J., \& Cohen, B. A. (2002). Qualifications of the public school teacher workforce: Prevalence of out-of-field teaching 1987-88 to 1999-2000 (NCES Publication No. 2002-603). Washington, DC: National Center for Education Statistics, U.S. Department of Education.

Smith, T. M., \& Ingersoll, R. M. (2004). What are the effects of induction and mentoring on beginning teacher turnover? American Educational Research Journal, 41, 681-714.

The Teaching Commission. (2006). Teaching at risk: Progress \& potholes. New York: Author.

Tourkin, S. C., Pugh, K. W., Fondelier, S. E., Parmer, R. J., Cole, C., Jackson, B., et al. (2004). 1999-2000 Schools and Staffing Survey (SASS) data file user's manual (NCES Publication No. 2004-303). Washington, DC: National Center for Education Statistics, U.S. Department of Education.

Wayne, A. J. (2000). Teacher supply and demand: Surprises from primary research. Education Policy Analysis 
Archives, 8(47). Retrieved March 25, 2004, from http://epaa.asu.edu/epaa/v8n47.html

Whitener, S. D., Gruber, K. J., Lynch, H., Tingos, K., Perona, M., \& Fondelier, S. (1997). Characteristics of stayers, movers, and leavers: Results from the Teacher Followup Survey, 1994-95 (NCES Publication No. 97450). Washington, DC: National Center for Education Statistics, U.S. Department of Education.

\section{ABOUT THE AUTHORS}

erling e. boe (CEC PA Federation), Professor of Education, Graduate School of Education, University of Pennsylvania, Philadelphia. LyNNe н. cook (CEC CA Federation), Dean, College of Education, California State University, Dominguez Hills. ROBERT J. SUNDERLAND, Rescarch Associate, Graduate School of Education, University of Pennsylvania, Philadelphia.
Support for this research was provided by Grant No. H0324C020002 from the U.S. Department of Education, Office of Special Education Programs; and by the Center for Research and Evaluation in Social Policy, the Graduate School of Education of the University of Pennsylvania. Statements do not reflect the position or policy of these agencies, and no official endorsement by them should be inferred.

Address correspondence to Erling E. Boe, Graduate School of Education, University of Pennsylvania, 3700 Walnut Street, Philadelphia, PA 19104 (e-mail: boe@pobox.upenn.edu).

Manuscript received October 2006; accepted August 2007.



